\title{
Isolation and Characterization Photo Degradation Impurities of Drug Product Olopatadine Hydrochloride by Spectral Techniques
}

\author{
Shivaji Jadhav" ${ }^{1, ~ *, ~ A m i t ~ G o s a r ~}{ }^{1}$, Amit Jadkar ${ }^{1}$, Rajesh Ankam ${ }^{2}$, Chandrakant Dhatrak ${ }^{2}$ \\ ${ }^{1}$ Indoco Remedies Ltd, R \& D Centre Rabale, Navi Mumbai, India \\ ${ }^{2}$ Glenmark Pharmaceuticals Ltd, Nasik, India
}

Email address:

shiva29us@yahoo.com (S. Jadhav),shivajij@indoco.com (S. Jadhav)

${ }^{*}$ Corresponding author

To cite this article:

Shivaji Jadhav, Amit Gosar, Amit Jadkar, Rajesh Ankam, Chandrakant Dhatrak. Isolation and Characterization Photo Degradation Impurities of Drug Product Olopatadine Hydrochloride by Spectral Techniques. Chemical and Biomolecular Engineering.

Vol. 4, No. 2, 2019, pp. 31-36. doi: 10.11648/j.cbe.20190402.11

Received: April 8, 2019; Accepted: May 8, 2019; Published: June 17, 2019

\begin{abstract}
Unknown impurities were detected during Photo degradation of Olopatadine Hydrochloride ophthalmic solution $0.5 \%(\mathrm{w} / \mathrm{v})$ when analyzed using the High performance liquid chromatographic technique with Photo Diode Array Detection. For further investigation was carried out by isolating these impurities from impurity rich sample of Olopatadine Hydrochloride ophthalmic solution $0.5 \%(\mathrm{w} / \mathrm{v})$ using preparative isolation technique. The Olopatadine Hydrochloride ophthalmic solution $0.5 \%(\mathrm{w} / \mathrm{v})$ was subjected to photolytic forced degradation in the presence of Benzalkonium chloride and other excipients like Hypromellose, Mannitol, Hydroxypropyl, Boric acid, Kollidon $30 \mathrm{LP}$ and mixture of solvents (Acetonitrile: Methanol; 1: $1(\mathrm{v} / \mathrm{v})$ under Ultra violet visible light. This led to the formation of the said impurities in higher concentration. This sample was then subjected to preparative HPLC for isolation of these unknown impurities. The structure of these unknown impurities was further elucidated using a different technique like Infra Ray Spectroscopy, Direct infusion (DI) Mass Spectroscopy, Ultra violet-Visible Spectroscopy, Proton Nuclear Magnetic Resonance Spectroscopy, carbon Nuclear Magnetic Resonance and Distortionless Enhancement by Polarization Transfer (DEPT) Spectroscopy which helped to confirm the structure of the impurities. Structure elucidation of the two impurities revealed that these are $\mathrm{E}$ and $\mathrm{Z}$ isomers of the Olopatadine hydrochloride Carbaldehyde. Olopatadine Z- isomer is used in the formulation of the Olopatadine Hydrochloride Ophthalmic Solution $0.5 \%(\mathrm{w} / \mathrm{v})$. The minor amount of E- isomer also remains present in this solution as a potential impurity. However, the amount of E-isomer may increase in the solution form due to racemization. Hence, the respective Carbaldehyde impurities (both $\mathrm{E}$ and $\mathrm{Z}$ isomers) are forming during Photolytic degradation. This formation is happening through photolytic Norrish type-1 reaction which is elaborated in the paper.
\end{abstract}

Keywords: Isolation, Characterization, NMR, E and Z Isomers, Olopatadine Hydrochloride Ophthalmic Solution, Carbaldehyde Impurities

\section{Introduction}

Olopatadine Hydrochloride is selective histamine H1 receptor antagonist and an inhibitor of the release of mediators including histamine from the human mast cells. Olopatadine hydrochloride ophthalmic solution is used to treat allergic conjunctival diseases. [1] Olopatadine hydrochloride ophthalmic solution $0.5 \%(\mathrm{w} / \mathrm{v})$ is a sterile ophthalmic solution containing Olopatadine for topical administration to the eyes. Olopatadine hydrochloride is a white, crystalline, water-soluble powder with a molecular weight of 373.88 and a molecular formula of $\mathrm{C}_{21} \mathrm{H}_{23} \mathrm{NO}_{3}$. $\mathrm{HCl}$ [2]

Since the impurity profile study of any pharmaceutical substance is a crucial part of process development, it was felt necessary to develop a reliable, High-Performance Liquid Chromatography method for identification and quantitative determination of impurities in Olopatadine Hydrochloride. 
[3-4] During force degradation studies, two unknown degradation impurities were detected in photodegradation of Olopatadine Hydrochloride, using a newly developed gradient reversed-phase High-performance liquid chromatography method. [5-6]. Identified impurities found in Olopatadine Hydrochloride Ophthalmic Solution $0.5 \%$ (w/v) can potentially exhibit pharmacological activity/toxicity. There are reporting, identification, and qualification thresholds dictated by ICH guidelines for allowed limits of related impurities. [7] A comprehensive study was undertaken for the identification of these impurities by isolation using preparative HPLC and further characterization by various spectroscopic techniques. [8]

Wide range of literature is available regarding related substances of Olopatadine Hydrochloride and most of these related substances are available in the market commercially, but none of them corresponds to the potential photodegradation impurities of Olopatadine Hydrochloride and hence comprehensive study was undertaken for isolation and identification of photodegradation impurities of Olopatadine Hydrochloride ophthalmic solution $0.5 \%$ (w/v) [9-10].

\section{Experimental}

Mobile phase A was prepared by taking $6.90113 \mathrm{gm}$ of Sodium dihydrogen phosphate in $1000 \mathrm{~mL}$ of water to this $1.0 \mathrm{~mL}$ of Triethylamine was added and $\mathrm{pH}$ was adjusted to 4.5 using orthophosphoric acid. Acetonitrile was used as Mobile Phase B and the gradient program was set as follows.

Table 1. Gradient Program.

\begin{tabular}{lll}
\hline Time (minute) & Mobile Phase-A (\%) & Mobile Phase-B (\%) \\
\hline 0 & 83 & 17 \\
10 & 83 & 17 \\
45 & 65 & 35 \\
50 & 52 & 48 \\
65 & 52 & 48 \\
66 & 83 & 17 \\
80 & 83 & 17 \\
\hline
\end{tabular}

Abbreviations: \% - Percentage.

Ultra violet on photodiode array detector spectra of all peaks was recorded from 200 to $400 \mathrm{~nm}$, and working wavelength was selected on $254 \mathrm{~nm}$ on waters alliance HPLC System. The Mass analyses were performed on Thermo Fisher scientific, Model LCQ Advantage LC-MS instrument. The HPLC column used was Symmetry shield RP8, (150 X $4.6 \mathrm{~mm}, 5.0 \mu \mathrm{m})$ The column temperature, wavelength, injection volume and run time were set to $30^{\circ} \mathrm{C}, 254 \mathrm{~nm}$, $20 \mu \mathrm{L}$ and 80 minutes respectively. The mobile phase flow rate was kept $1.0 \mathrm{~mL} /$ minute.

A preparative HPLC separation was carried out using a Mobile phase consisted of A: Buffer: $10 \mathrm{gm}$ ammonium acetate in 10 Liter water, $5 \mathrm{~mL}$ Formic acid. B: Acetonitrile respectively with a Photo Diode Array detector with make Waters and Model: 2767, 2487, CFO, 2525. The column Water Symmetry $(150 \times 30 \mathrm{~mm}, 5 \mu \mathrm{m}, \mathrm{C} 8)$ was operated at ambient temperature the flow rate was maintained at $40 \mathrm{~mL} /$ minute and detection was $254 \mathrm{~nm}$. The Gradient program as below Table No: 2

Table 2. Gradient Program.

\begin{tabular}{lll}
\hline Time (minute) & Mobile Phase-A (\%) & Mobile Phase-B (\%) \\
\hline 0.0 & 75 & 25 \\
8.50 & 68.50 & 31.50 \\
8.60 & 50 & 50 \\
11 & 50 & 50 \\
12 & 75 & 25 \\
15 & 75 & 25 \\
\hline
\end{tabular}

Abbreviations: \% - Percentage.

\section{Result \& Discussion}

Olopatadine Hydrochloride ophthalmic solution; after Photo degradation contained two unknown impurities at Relative Retention time $0.39 \& 0.42$ respectively. Our objective of this study was to identify and isolated impurities in pure form and characterize these impurities. For which plan of the study was decided as follows.

For identifying impurity, it was decided to scan the peak of an impurity using Photo Diode Array detector to get characteristic Ultra violet spectra which would be helpful during preparative isolation.

For isolation of impurities, the degraded sample to be generated which containing required impurities in sufficient amount. This would be done by Ultra violet light in presence of Benzalkonium chloride, Excipients like Hypromellose, Manito, Hydroxypropyl, Boric acid, Kollidon 30 LP and mixture (1: 1) of Methanol and Acetonitrile degradation studies of the drug product. After having impurity (at Relative Retention time $0.39 \& 0.42$ ) rich sample, a preparative High-performance Liquid Chromatography method would be developed for isolation of the said impurity. Isolated impurities should be first confirmed by original High-performance Liquid Chromatography method (by Relative Retention time and Photo Diode Array scan) and by mass spectral analysis Direct infusion (DI). Further characterization would be carried out using spectral techniques such as ${ }^{1} \mathrm{H}$ - Nuclear Magnetic Resonance, ${ }^{13} \mathrm{C}$ Nuclear Magnetic Resonance, and Fourier Transmittance Infrared spectroscopy.

After obtaining spectral data probable structural elucidation would be carried out.

\subsection{Force Degradation Studies}

Ultra violet light degradation of Olopatadine Hydrochloride Ophthalmic solution in presence of Benzalkonium chloride, excipients like Hypromellose, Manito, Hydroxypropyl, Boric acid, Kollidon 30 LP and Methanol: Acetonitrile (1: 1) was carried out and degraded samples were analyzed using the original High-performance Liquid Chromatography method. From degradation experiment it was found that the desired impurity was generated in substantial amount during Ultra violet light 
degradation in presence of Benzalkonium chloride, excipients like Hypromellose, Mannitol, Hydroxypropyl, Boric acid, Kollidon 30 LP and Methanol: Acetonitrile (1: 1). The experimental details of forced degradation studies where a substantial amount of desired impurities formed as mentioned in below Table No: 3

These experiments used for preparative HPLC for impurity isolation.

Table 3. Force degradation study.

\begin{tabular}{llll}
\hline Expt. No. & Sr. No. & Sample Preparations & Relative Retention Time 0.39 \\
\hline & & Relative Retention Time 0.42 \\
\hline & 01 & $\begin{array}{l}\text { Benzalkonium chloride }+25 \mathrm{~mL} \text { mixture of Methanol: } \\
\text { Acetonitrile }(1: 1)+\text { about } 1 \text { gm above excipient and } \\
\text { kept this solution at Ultra violet light }\end{array}$ & $12.14 \%$ \\
\hline
\end{tabular}

Abbreviations: \% - Percentage.

\subsection{Preparative HPLC}

A preparative HPLC method was developed for isolation of impurity at Relative Retention Time 0.39 and 0.42 using a volatile buffer. For confirmation of usability of preparative HPLC method, impurity (Relative Retention Time 0.39 and 0.42) rich Olopatadine Ophthalmic solution obtained by degradation was subjected to preparative isolation. Isolated impurity (at Relative Retention Time 0.39 and 0.42) was further confirmed by the original High-performance Liquid Chromatography method by means of High-performance Liquid Chromatography Relative Retention Time, Photo Diode Array scan (Ultra violet spectrum) and by Mass Direct infusion (DI).

Desired fractions from Preparative. HPLC was collected and the solvent removed from the fractions by lyophilization at $-55^{\circ} \mathrm{C}$ and analyzed by the analytical High-Performance Liquid chromatography method to confirm Relative Retention Time 0.39 and 0.42 . From the data, it was found that the collected fraction was matching with High Performance Liquid chromatography Relative Retention Time 0.39 and 0.42 and same was cross-checked with Photo Diode Array scan ( $\tau$ maxima is $254 \mathrm{~nm}$ ). Same fraction was analyzed by Mass Direct infusion and found that the mass value is 308.15 and 308.18 .

\subsection{Reaction Pathway: Systematic Pathway of Olopatadine Carbaldehyde Impurity}
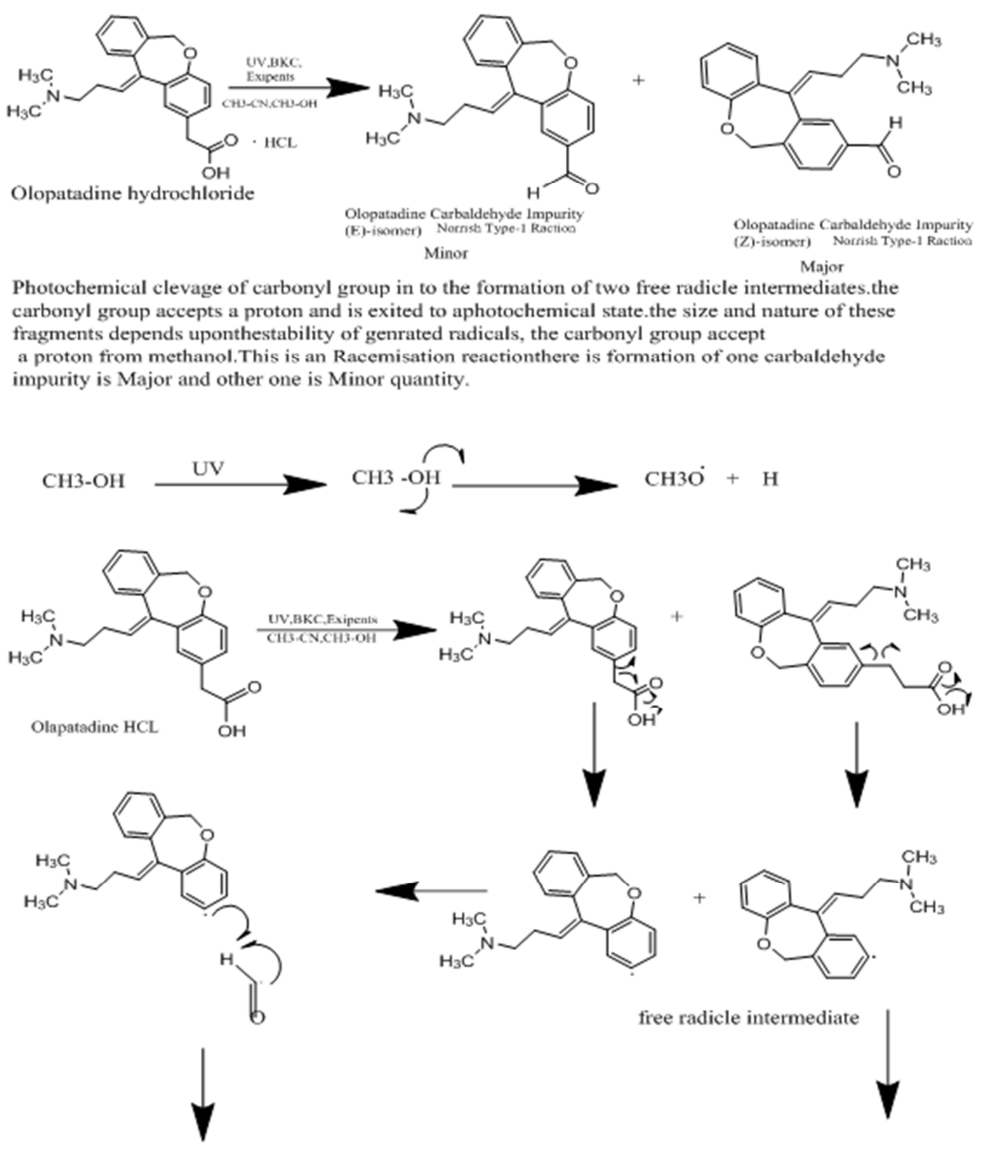

Franments can simply recombine to the carbonyl gruop with racemisation and formation of Olopatadine (Z)-isomer which also subsequently converted in to Olpatadine (E)-isomer. 


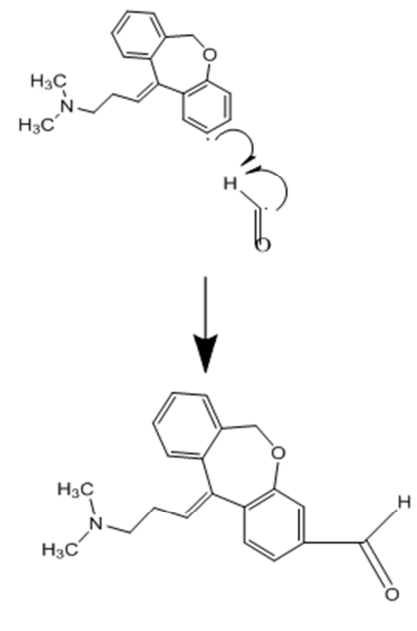

Olapatadine (E)-isomer

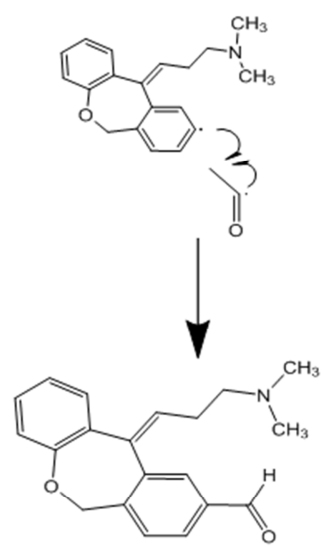

Olapatadine (z)-isomer.

Figure 1. REACTION PATHWAY.

\subsection{Salt Preparation of Impurities to Isolate Them into Solid form}

The isolated impurity at Relative Retention Time 0.42 is dissolved in $10 \mathrm{~mL}$ Acetone and $\mathrm{pH}$ adjusted to acidic mixture of Isopropyl Alcohol: Hydrochloric acid. After addition of Isopropyl Alcohol: Hydrochloric acid the impurity get precipitated out, this impurity filtrate with 41 number Whatman filter paper.

\subsection{Charaterization of Isolated Impurities}

The isolated impurity was further analyzed by spectral (Ultra violet, ${ }^{1} \mathrm{H}$, and ${ }^{13} \mathrm{C}$-Nuclear magnetic Resonance, Mass Direct infusion and Infrared radiation methods.

Isolated impurity obtained from Preparative HPLC was analyzed by using High Performance Liquid chromatography method in terms of Photo Diode Array scan, Relative Retention Time and Mass Direct infusion (DI).

The impurity was analyzed by Infrared radiation, make Shimadzu, model IR Affinity 1S, For impurity at Relative Retention Time 0.39, $\mathrm{C}=\mathrm{O}$ Aldehyde stretching at wavenumber $1685.79 \mathrm{~cm}^{-1}$ and impurity at Relative Retention Time $0.42, \mathrm{C}=\mathrm{O}$ Aldehyde stretching at wavenumber $1681.93 \mathrm{~cm}^{-1}$, by Ultra violet spectrophotometer, Make Perkin Elmer, model Lambda 35, For impurity at Relative Retention Time 0.39 sample preparation as $10 \mathrm{mg}$ sample was dissolved in $100 \mathrm{ml}$ water. Take $1 \mathrm{~mL}$ of above solution dissolve in 10 $\mathrm{mL}$ water and the Ultra violet spectrum was recorded in the range 400-200 nm. Ultra violet $\tau$ max was observed at 287 $\mathrm{nm}$. For impurity at Relative Retention Time 0.42 sample preparation as $10 \mathrm{mg}$ sample was dissolved in $100 \mathrm{~mL}$ water. Take $1 \mathrm{~mL}$ of above solution dissolve in $10 \mathrm{~mL}$ water and the Ultra violet spectrum was recorded in the range 400-200 nm. Ultra violet $\tau$ max was observed at $287 \mathrm{~nm}$. By mass spectrophotometer the impurity sample was analyzed by using direct infusion (DI) method, Make: Thermo fisher scientific, Model: LCQ Advantage. For impurity at RRT 0.39 $\mathrm{m} / \mathrm{z}$ was $308.15(\mathrm{~m}+\mathrm{H})$. For impurity at Relative Retention Time $0.42 \mathrm{~m} / \mathrm{z}$ was $308.18(\mathrm{~m}+\mathrm{H})$.

By TGA analysis used Make as TA instrument and Model Q500, sample preparation and instrument condition as,
$5.5480 \mathrm{mg}$ of sample was taken in platinum pan, equilibrate at $30.0^{\circ} \mathrm{C}$, ramp $10.00^{\circ} \mathrm{C} / \mathrm{min}$ to $800.0{ }^{\circ} \mathrm{C}$, isothermal for 0.50 minute and result was found as impurity at Relative Retention Time 0.39 . Weight loss at $105^{\circ} \mathrm{C}$ was $4.546 \%$, total weight loss up to $800^{\circ} \mathrm{C}$ was $95.11 \%$ \& Ash Content was $0.344 \%$. For impurity at Relative Retention Time 0.42 , Weight loss at $105^{\circ} \mathrm{C}$ was $0.04762 \%$, Total weight loss up to $800^{\circ} \mathrm{C}$ was $98.76 \%$ and Ash content was $1.19238 \%$.

${ }^{1} \mathrm{H}$ Nuclear Magnetic Resonance Chemical Shift Assignments for impurity at Relative Retention Time 0.39 and impurity at Relative Retention Time 0.42 in Table No.04 which was recorded under instrument make Bruker, Model 400 Ultra shields.

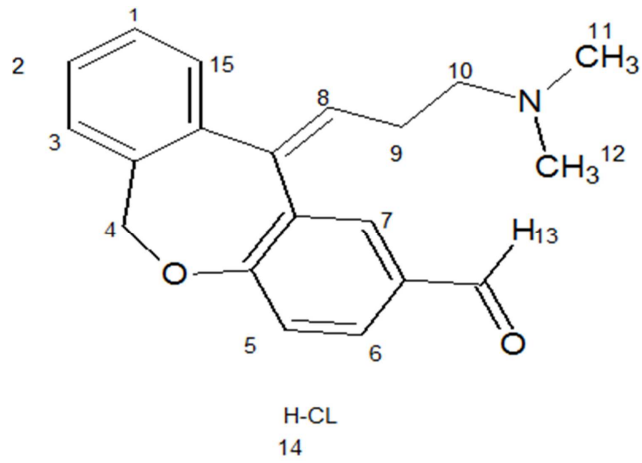

Figure 2. Impurity at RRT 0.39.

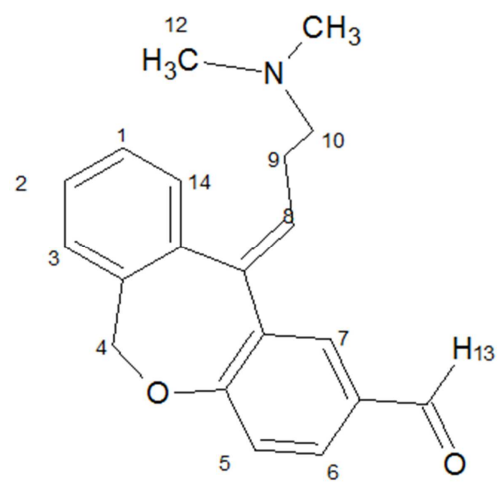

Figure 3. Impurity at RRT 0.42 . 
Table 4. ${ }^{1}$ H Nuclear Magnetic Resonance Chemical Shift Assignments.

\begin{tabular}{llll}
\hline \multicolumn{2}{l}{ Impurity at Relative Retention Time } & \multicolumn{2}{l}{ Impurity at Relative Retention Time } \\
\hline Assignment & Chemical shift $(\boldsymbol{\delta}) \mathbf{p p m}$ & Assignment & Chemical shift $(\boldsymbol{\delta}) \mathbf{p p m}$ \\
\hline $1(1 \mathrm{H}), 3(1 \mathrm{H})$ & $7.40-7.44$ & $1(1 \mathrm{H})$ & $7.73-7.74$ \\
$2(1 \mathrm{H})$ & $7.33-7.38$ & $2(1 \mathrm{H})$ & $7.22-7.27$ \\
$4(2 \mathrm{H})$ & 4.89 & $3(1 \mathrm{H}), 15(1 \mathrm{H})$ & $7.31-7.42$ \\
$5(1 \mathrm{H})$ & $7.26-7.27$ & $4(2 \mathrm{H})$ & $5.33-5.70$ \\
$6(1 \mathrm{H})$ & $7.28-7.29$ & $5(1 \mathrm{H})$ & $6.98-7.00$ \\
$7(1 \mathrm{H})$ & $7.85-7.86$ & $6(1 \mathrm{H})$ & 7.76 \\
$8(1 \mathrm{H})$ & $6.10-6.13$ & $7(1 \mathrm{H})$ & $6.86-6.88$ \\
$9(1 \mathrm{H})$ & 2.84 & $8(1 \mathrm{H})$ & $5.72-576$ \\
$10(1 \mathrm{H})$ & 2.97 & $9(2 \mathrm{H})$ & $2.89-2.94$ \\
$11,12(6 \mathrm{H})$ & 2.16 & $10(1 \mathrm{H})$ & $3.30-3.40$ \\
$13(1 \mathrm{H})$ & 9.80 & $11,12(6 \mathrm{H})$ & 2.87 \\
$14(1 \mathrm{H})$ & $7.63-7.66$ & $13(1 \mathrm{H})$ & 9.85 \\
- & - & $14(1 \mathrm{H})$ & $\mathrm{H}-\mathrm{Cl}$ \\
\hline
\end{tabular}

Abbreviations: ppm - parts per million.

${ }^{13} \mathrm{C}$ Nuclear Magnetic Resonance Chemical Shift Assignments for impurity at Relative Retention Time 0.39 and impurity at Relative Retention Time 0.42 in Table No. 05 which was recorded under instrument make Bruker, Model 400 Ultra shields.

Table 5. ${ }^{13}$ C Nuclear Magnetic Resonance Chemical Shift Assignments.

\begin{tabular}{|c|c|c|c|c|c|}
\hline \multicolumn{3}{|c|}{ Impurity at Relative Retention Time 0.39} & \multicolumn{3}{|c|}{ Impurity at Relative Retention Time 0.42} \\
\hline Assignment & Chemical shift (ס) ppm & DEPT & Assignment & 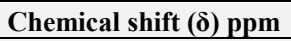 & DEPT \\
\hline 1 & 121.20 & 121.20 & 1 & 130.35 & 130.36 \\
\hline 2 & 128.89 & 128.89 & 2 & 129.17 & 129.17 \\
\hline 3 & 129.34 & 129.35 & 3 & 126.60 & 126.61 \\
\hline 4 & 129.02 & - & 4 & 135.20 & - \\
\hline 5 & 71.57 & 71.57 & 5 & 71.37 & 71.37 \\
\hline 6 & 135.08 & - & 6 & 134.98 & - \\
\hline 8 & 129.58 & 129.57 & 8 & 120.78 & 120.79 \\
\hline 9 & 130.14 & 130.14 & 9 & 127.02 & 127.02 \\
\hline 10 & 131.02 & 131.02 & 10 & 129.44 & 129.45 \\
\hline 11 & 131.48 & 131.49 & 11 & 128.71 & 128.72 \\
\hline 12 & 140.61 & - & 12 & 124.18 & - \\
\hline 13 & 131.91 & 131.91 & 13 & 144.57 & - \\
\hline 14 & 134.46 & 134.47 & 14 & 130.28 & 130.29 \\
\hline 15 & 161.97 & - & 15 & 104.26 & 104.26 \\
\hline 17 & 28.43 & 28.43 & 17 & 58.11 & 58.04 \\
\hline 18,19 & 45.15 & 45.15 & 18,19 & 43.42 & 43.40 \\
\hline 20 & 192.67 & 192.67 & 20 & 157.16 & - \\
\hline
\end{tabular}

Abbreviations: ppm - parts per million, RRT - Relative Retention Time.

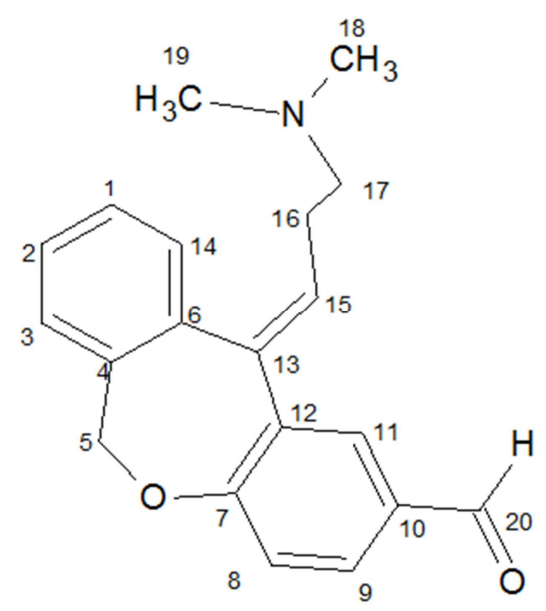

Figure 4. Impurity at RRT 0.39.<smiles>CN(C)[14CH2]C/C=C1\c2ccccc2COc2ccc(C=O)cc21</smiles>

Figure 5. Impurity at RRT 0.42 .

Based on Infrared radiation, Direct infusion, Ultra violet, ${ }^{1} \mathrm{H}$ Nuclear Magnetic Resonance and ${ }^{13} \mathrm{C}$ Nuclear Magnetic Resonance spectral data for compound, below structure can be confirmed for,

(E)-11-[3-(dimethylamino) propylidene]-6, 11- 
dihydrodibenzo [b, e] oxepine-2-carbaldehyde.

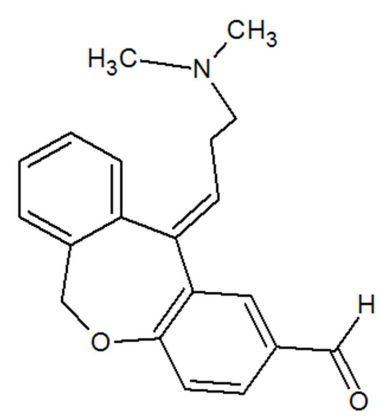

Figure 6. Structure of Olopatadine carbaldehyde (E) isomer. (Impurity at RRT 0.39).

(Z)-11-(3-(dimethylamino) propylidene)-6, $11-$ dihydrodibenzo $[\mathrm{b}, \mathrm{e}]$ oxepine-2-carbaldehyde

Hydrochloride

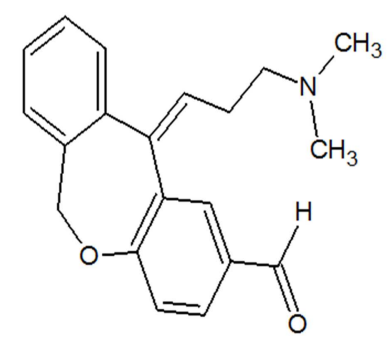

$\mathrm{HCl}$

Figure 7. Structure of Olopatadine carbaldehyde $\mathrm{HCl}$ (Z) isomer. (Impurity at RRT 0.42).

\section{Conclusion}

Two unknown impurities observed in the Olopatadine Hydrochloride ophthalmic solution $0.5 \%(\mathrm{w} / \mathrm{v})$ during forced degradation study, were successfully prepared by preparative isolation technique. This is achieved by enriching the impurities in the Olopatadine Hydrochloride ophthalmic solution $0.5 \%$ $(\mathrm{w} / \mathrm{v})$ by reacting with Benzalkonium chloride in the presence of other excipients like Hypromellose, Mannitol, Hydroxypropyl, Boric acid, Kollidon 30 LP and Methanol: Acetonitrile (1: 1) and Ultra violet visible light. The photolytic degradation yielded $\mathrm{Z}$ and $\mathrm{E}$ isomers of carbaldehyde impurities, out of which the Carbaldehyde Z-isomer was reported to be a possible impurity as per USP 41 [10]; however, the Carbaldehyde E-isomer was first time identified.

Since Olopatadine Z-isomer is an active drug and E-isomer is always present in very small quantity either as per impurity or form due to racemization the corresponding amount of Carbaldehyde $\mathrm{Z}$ and $\mathrm{E}$ isomer were formed in the reaction.

The proposed structures are further confirmed using various spectral techniques such as NMR, IR, Mass, spectroscopy. The mechanism of formation of these impurities in Olopatadine Hydrochloride ophthalmic solution $0.5 \%(\mathrm{w} / \mathrm{v})$ as described in Norrish Type-1 reaction mechanism.

\section{Acknowledgements}

The Authors wish to extend their gratitude to Indoco Remedies Ltd and Glenmark pharmaceutical ltd. for providing all kind of support. The Author wish to thank all our colleagues who provided technical assistance during research work and during compiling data.

\section{References}

[1] Tamura, T., 2012. Olopatadine ophthalmic solution suppresses substance P release in the Conjunctivitis models. Asia Pacific Allergy, 2 (2), pp. 115-121.

[2] Abelson, M. B., \& Welch, D. L. (2000). An evaluation of onset and duration of action of Patanol ${ }^{\circledR}$ (olopatadine hydrochloride ophthalmic solution $0.1 \%$ ) compared to Claritin $\mathbb{R}$ (loratadine $10 \mathrm{mg}$ ) tablets in acute allergic conjunctivitis in the conjunctival allergen challenge model. Acta Ophthalmologica Scandinavica, 78, 60-63.

[3] Maksić, J., Jovanović, M., Rakić, T., Popović, I., Ivanović, D., \& Jančić-Stojanović, B. (2014). Chromatographic analysis of olopatadine in hydrophilic interaction liquid chromatography. Journal of chromatographic science, 53 (5), 680-686.

[4] Limbachiya, U. N., Patel, N. N., Nikesh, R., KS, R., Patel, S., \& Shinde, G. (2013). Analytical Method Development and Validation for Simultaneous Determination of Ambroxol and Olopatadine Hydrochloride in Synthetic Mixture. Asian Journal of Research in Chemistry, 6 (4), 389-392.

[5] Ahluwalia, V. K. (2009). Green chemistry: environmentally benign reaction. Ane Books Pvt Ltd.

[6] Mahajan, A. A., Mohanraj, K., Kale, S., \& Thaker, A. K. (2013). STUDY OF OLOPATADINE HYDROCHLORIDE UNDER ICH RECOMMENDED STRESS CONDITIONS BY LC, LC-MS/TOF FOR IDENTIFICATION, AND CHARACTERIZATION OF DEGRADATION PRODUCTS. Journal of Liquid Chromatography \& Related Technologies, 36 (13), 1881-1898. Kłos, K., Czerniec-Michalik, E.

[7] Guideline, I. H. T. (2006). Impurities in new drug products. Q3B (R2), current step, 4, 1-5.

[8] United States Pharmacopeia, USP41-NF36. 2018. Olopatadine Hydrochloride ophthalmic solution.

[9] AlAani, H., \& AlNukkary, Y. (2016). Determination of Benzalkonium Chloride in Ophthalmic Solutions by StabilityIndicating HPLC Method: Application to a Stability Study. Journal of Applied Pharmaceutical Science Vol, 6 (05), 080089.

[10] SAHOO, D. K., PATRO, S. S., \& MOHAPATRA, S. METHOD DEVELOPMENT AND VALIDATION FOR THE ESTIMATION OF OLOPATADINE IN BULK AND PHARMACEUTICAL DOSAGE FORMS AND ITS STRESS DEGRADATION STUDIES USING UV-VIS SPECTROPHOTOMETRIC METHOD. 